\title{
Factor structure, reliability and validity of the Parental Support for Learning Scale: \\ Adolescent Short Form (PSLS-AS)
}

\begin{abstract}
Parental involvement in children's learning has been found to influence academic success. However, very few tools exist for measuring parental involvement, particularly ones that target adolescents' self-report. The present study assessed the factor structure, reliability and convergent validity of a new scale to assess adolescents' perceptions of their mothers' and fathers' educational involvement: the Parental Support for Learning Scale: Adolescent Short Form (PSLS-AS). The PSLS-AS, as well as a questionnaire measuring the risk of high school drop-out, was administered to a sample of 825 youth (aged 13-14 years). Exploratory factor analysis revealed a two-factor structure representing parental involvement: Controlling Involvement and Autonomy Supportive Involvement. Adolescents' perceptions of their parents' involvement correlated with a risk of high school drop-out. Implications and future directions for further validation of the PSLS-AS are discussed.
\end{abstract}

Keywords Adolescence $\cdot$ Autonomy support $\cdot$ Children's learning $\cdot$ Factor analysis $\cdot$ Fathers ·

Mothers $\cdot$ Parental control $\cdot$ Parental involvement $\cdot$ Scale development $\cdot$ Self- report

\section{Introduction}

Parental involvement in children's learning exerts a powerful influence on school success across grade levels (for meta-analyses, see Fan and Chen 2001; Hill and Tyson 2009). The nature and quantity of parental involvement shifts as children move from elementary school into middle and high school (Green et al. 2007), because the school curriculum and the psychological needs of children change dramatically during these years. Consequently, researchers have called for more attention to understanding parental academic involvement during adolescence (Shumow 
and Miller 2001), yet few measurement tools are available to assess this important construct during the adolescent period. To address this issue, we present the factor structure, reliability and convergent validity of a scale designed to assess adolescents' perceptions of parental involvement in learning during the early adolescent period.

\section{Parental involvement in children's learning}

Parental involvement in children's learning can be broadly defined as parent-child interactions that are intended to promote school success (El Nokali et al. 2010; Park and Holloway 2013; Rogers et al. 2009). In general, parental involvement can be classified in terms of direct behaviours and emotional tone (Rogers et al. 2014). Direct parental involvement behaviours (e.g. supervision of homework) tend to decline as children move from elementary school into middle and high school (Green et al. 2007). Such a decline in parental involvement in middle and high school can be attributed to both changes in the school con- text and to the normal developmental changes that occur during adolescence. As the school curriculum becomes more complex, parents' abilities to stay actively involved in their children's schoolwork can be challenged (Eccles and Harold 1996; Hill and Tyson 2009; Sanders and Epstein 2000). In addition, early adolescence is associated with major developments in terms of cognition and selfconcept (Adams and Berzonsky 2003; Sebastian et al. 2008). That is, adolescents increasingly are better able to integrate knowledge derived from their own previous successes and failures in order to make decisions and to coordinate the pursuit of multiple educational and personal goals (Byrnes et al. 1999; Falbo et al. 2001). Moreover, as children become more autonomous, they can have less desire for parental engagement in school-related activities and supervision of academic work (Seginer 2006). As a result of such changes, the direct forms of parental involvement that might have been necessary with young children become less relevant and 
effective as children develop (Sanders and Epstein 2000).

Despite the decrease in direct parental involvement behaviours as children develop, parents still might communicate involvement and interest in their children's learning via their emotional tone and style of interactions. In both middle childhood and adolescence, supportive and encouraging parental involvement (e.g. warmth, providing praise, supporting autonomy) is associated with better school outcomes in children (Simpkins et al. 2006), whereas coercive interactions and the use of commands or punishment are negatively associated with school success (Grolnick et al. 2002; Niggli et al. 2007). It has been suggested that supportive parental involvement positively impacts children's achievement by improving both skill development and the child's intrinsic motivation for learning, while con- trolling or punitive involvement can undermine an adolescent's sense of competence and autonomy and lead to decreased motivation to learn (Pomerantz et al. 2007).

Despite the change in parental involvement over the course of childhood, it remains an important predictor of school outcomes throughout high school, including higher grades, better attendance, lower dropout, increased motivation and better adaptation (see Gonzales- DeHass et al. 2005, for a review). Despite the developmental shifts during the adolescent period with regards to learning, current measurement tools for parental involvement do not reflect these developmental variations (Hill and Taylor 2004). Indeed, the literature on parental support is largely focused on students before high school. In a review of 17 parental involvement measurement tools, Westmoreland et al. (2009) identified only one that assesses adolescent selfreport, and a current review of the literature did not produce any newer tools. The Home Observation for Measurement of the Environment (HOME) Inventory (Bradley et al. 2000) is the only existing measure of adolescents' learning environment; however, the tool does not assess 
the independent involvement of both mothers and fathers. It is important to examine adolescents' perceptions of both parents' involvement, as their perceptions of the family environment can vary substantially from their parents (Loeber et al. 1990; van Assema et al. 2007), and it allows the adolescent to convey his or her own viewpoint. Given that parental involvement in this period is a known protective factor against various negative outcomes, such as high school dropout, it follows that understanding adolescents' views of their parents' involvement in their academics could be important for creating and implementing family or school-based interventions to help to improve academic outcomes for these children.

Although most studies of parental involvement in learning have been based on maternal involvement, fathers' involvement in children's schooling has been linked to higher achievement and positive school attitudes for young children (Flouri et al. 2002; McBride et al. 2005), beyond the impact of mothers' involvement (Grief and Grief 2004). Although it has been studied in children, demonstrating the importance of father involvement, this research has yet to be extended to the adolescent population.

\section{Objectives of the present study}

There is a clear need for measurement tools to assess parental involvement in learning during the adolescent period, as well as to differentially examine father and mother involvement. To address this gap, there were five objectives for this study: (1) to adapt an existing scale, the Parental Support for Learning Scale, to be more relevant to the adolescent period, (2) to examine the factor structure of the items with data from a large sample of adolescents, (3) to examine the internal consistency of the resultant factors, (4) to examine the convergent validity of the scale by examining its association with a related construct, namely, the risk of high school dropout and (5) to provide a questionnaire that allows separate reports of mother and father involvement in 
adolescents' learning.

\section{Methods}

\section{Participants and procedure}

Participants in the current study were 825 grade 9 students from 15 public high schools in a large Canadian city. For the total sample, the mean age was 13.37 years and 362 were boys (mean age 13.41 years) and 463 were girls (mean age 13.34 years). Of these, 768 (92.4\%) spoke English at home, 252 (30.3\%) spoke French at home and 108 (13.0\%) spoke another language at home. Despite some linguistic diversity in the sample, all participating students attended Anglophone schools where English was the main language of instruction. The majority of participants indicated Canada (95.3\%) as their country of birth, followed by other (3.5\%) and United States (1.2\%).

Participants were recruited as part of a larger longitudinal project on coping with stress. Students brought home a parental consent form detailing the research purposes and procedures. Of the students who returned consent forms, $67 \%$ agreed to participate. Participants at each school were brought to a common area in the school (e.g. cafeteria, library) in groups of approximately 20, and were presented with an envelope that contained a student assent form and questionnaires. Instructions were read aloud by a research assistant and participants responded individually.

\section{Measurement}

The Parental Support for Learning Scale (PSLS) was developed by Rogers et al. (2014) to assess children's perceptions of their mothers' and fathers' educational involvement in the home. The original version of this scale was used to assess elementary school-aged children's perceptions and revealed a stable factor structure and demonstrated strong psycho- metric 
properties (Rogers et al. 2014).

For the present study, the PSLS was modified with two goals in mind: (1) to make the scale appropriate for adolescent self-report and (2) to reduce the length so that it could be easily completed in 10-15 min. Consistent with existing research about parental involvement in the adolescent period, items from the original scale about parental participation with homework and active management of the learning environment were excluded. Items reflecting the tone or style of parents' involvement were modified slightly and new ones added based on extant literature to reflect the learning experiences of older children. The resultant version, the Parental Support for Learning Scale—Adolescent Short Form (PSLS- AS), was a 22-item questionnaire assessing adolescent's reports of their mothers' and fathers' behaviours that are specifically aimed at helping them to succeed at school. It uses a 5-point Likert-type scale ranging from 1 (strongly disagree) to 5 (strongly agree). Participating students responded to two versions of the PSLS-AS items: one relating to interactions with their mother and one to interactions with their father. Participating students also completed the Questionnaire d'évaluation du décrochage en milieu scolaire: English version (DEMS; Potvin et al. 2004) to assess the risk of high school dropout based on five domains: parental involvement, attitude towards school, perception of school achievement, parental supervision, and academic aspirations. The inventory consists of 33 questions with multiple-choice responses and takes approximately 15 min to complete. Previous research has shown that the DEMS has good internal reliability, test-retest reliability and validity (Potvin et al. 2004, 2009). For the current sample, the internal consistencies were moderate to excellent (Cronbach's alphas ranged from 0.56 to 0.88 ).

\section{Data analytic plan}

To examine the factor structure of the mother and father forms of the PSLS-AS, 
exploratory factor analysis was performed for the 22 items of the questionnaire. The criterion chosen to determine that an extracted factor accounted for a reasonably large proportion of the total variance was based on an eigenvalue greater than 1 and an evaluation of scree- plots. An exploratory factor analysis using oblique rotations was chosen because it was anticipated that extracted factors were likely to be correlated. An item-factor loading of 0.40 or higher was determined for retention. This level is consistent with other literature and accepted statistical norms (Tabachnick and Fidell 1996) and is based on the ration- ale of generating the most complete psychological interpretation of the data. To examine the convergent validity, bivariate (Pearson) correlations were conducted with the PSLS-AS factors and the DEMS subscales to assess expected relationships with related constructs.

\section{Results}

\section{Preliminary analyses}

The Kaiser-Meyer-Olkin (KMO) measure of sampling adequacy and the Bartlett Test of Sphericity (BTS) were conducted on the data prior to factor extraction to ensure that the characteristics of the data set were suitable for the factor analysis to be conducted. For the PSLS-AS-Mother, KMO analyses indicated an index of 0.93 , and consistent with a highly significant BTS $\left.\chi^{2}=5752.54, p<0.001\right)$. For the PSLS-AS-Father, KMO analyses indicated an index of 0.93 , and consistent with a highly significant BTS $\left(\chi^{2}=5626.34, p<0.001\right)$. Very skewed items were eliminated from the questionnaire. These preliminary analyses satisfied the psychometric criteria for factor analysis to be performed based on data distribution characteristics.

\section{Factor analysis}

Following extraction and oblique rotation, two factors with eigenvalues greater than 
1 emerged from analysis of both the mother and father versions of the PSLS-AS (see Tables $\underline{1}$,

2). Responses to the items combined into similar factors with low to moderate inter-item correlations. Both versions of the scale resulted in similar factor structures but with slight variations in the number of items per factor and the strength of each factor loading. For the PSLS-AS-Mother, the factors accounted for $50 \%$ of the variance and included Factor 1:

Controlling Involvement (12 items) and Factor 2: Autonomy Supportive Involvement (8 items). The PSLS-AS-Father accounted for $52 \%$ of the variance and consisted of Factor 1: Autonomy Supportive Involvement (8 items) and Factor 2: Controlling Involvement (11 items). Factor loadings of the PSLS-AS-Mother items in relation to the two-factor solution are shown in Table $\underline{1}$ and the factor loading of the PSLS-AS-Father items for the two factors are shown in Table $\underline{2}$. The Cronbach's alpha internal reliability coefficients for the factors were high (ranging from 0.87 to 0.90$)$.

\section{Convergent validity}

Correlations between the two-factor PSLS-AS and the DEMS (total score and subscales) are shown in Table $\underline{3}$. The correlations between the PSLS-AS factors and the DEMS scores ranged from 0.32 to 0.51 and all were highly significant at $(\mathrm{p}<0.001)$, providing evidence for the convergent validity of the PSLS-AS factors. The pattern of results indicate that, in general, adolescents' perceptions of their parents' autonomy support for learning tended to correlate with a lower risk of high school dropout, whereas perceptions of parental control correlated with higher risk of high school dropout for both mother and father involvement.

\section{Discussion}

The overall objective of this study was to present the factor structure, reliability and convergent validity of a new scale to assess adolescent's perceptions of their mothers' and 
fathers' educational involvement: The Parental Support for Learning Scale: Adolescent Short Form (PSLS-AS). A large sample of adolescents completed the PSLS-AS and another scale measuring risk of high school dropout. Factor analyses of PSLS-AS data resulted in a stable twofactor structure for mother and father forms: (1) Controlling Parental Involvement and (2) Autonomy Supportive Involvement. Reliability analyses indicated excellent internal consistency of the factors. Moreover, the scale showed strong associations with various indicators of high school dropout, demonstrating convergent validity.

The Controlling Involvement factor of the PSLS-AS focuses on adolescents' perceptions that their parents use commands, punishment, nagging and disapproval regarding their schoolwork. A close examination of these items shows that the majority of statements reflect control strategies that are psychological in nature, as opposed to more behavioural control strategies. This is an important distinction, because a robust body of parenting literature demonstrates that psychologically-controlling parenting in adolescence is associated with a range of negative outcomes, including internalising and externalising problems (see Soenens and Vansteenkiste 2010, for a review). As suggested in this study, when applied to adolescents' learning and schoolwork, these negative outcomes can be associated with an increased risk of high school dropout.

By contrast, the Autonomy Supportive Involvement factor of the PSLS-AS focused on adolescents' perceptions of their parents as warm, patient, and providing independence around school-related choices. Previous research has revealed that these parenting strategies foster adolescents' sense of competence and motivation (Pomerantz et al. 2007), and some studies have suggested a sense of security and connectedness between adolescents and their parents (Gonzales-DeHass et al. 2005). When parents act in autonomy-supportive ways, their children 
tend to be more positive about their own autonomy and competence, and have higher levels of self-determined motivation. In turn, children with higher self- determined motivation are more likely to complete high school than their peers with lower self-determined motivation (Hardre and Reeve 2003).

The present study provides preliminary evidence that the PSLS-AS could be a promising tool for sensitively assessing adolescents' perceptions of parental involvement. Parental involvement in the home can play an important role in the learning of youth, even as perceived by teachers (Izzo et al. 1999). Moreover, effective parental involvement in the home can have important benefits that extend to other learning environments, such as the class- room setting (Hornby 2011). The PSLS-AS is short and can be completed in 10-15 min, differentially assesses perceptions of maternal and paternal involvement, has good internal reliability, and is related to expected constructs. Despite this promise, it is important to note that, because the PSLS-AS is not yet standardised, normed scores are not available for clinical use. Moreover, additional research is needed to further validate the PSLS-AS, such as by examining the factors in relation to actual dropout rates, as well as other important variables, such as motivation, academic outcomes and additional aspects of family functioning. 


\section{References}

Adams, G. R., \& Berzonsky, M. D. (2003). Blackwell handbook of adolescence. Malden, MA: Blackwell.

Bradley, R. H., Corwyn, R. F., Caldwell, B. M., Whiteside-Mansell, L., \& Mink, I. T. (2000). Measuring the home environments of children in early adolescence. Journal of Research on Adolescence, 10(3), 247-288.

Byrnes, J. P., Miller, D. C., \& Reynolds, M. (1999). Learning to make good decisions: A selfregulation perspective. Child Development, 70, 1121-1140.

Eccles, J., \& Harold, A. (1996). Family involvement in children's and adolescents' schooling. In A. Booth \& J. Dunn (Eds.), Family-school links: How do they affect educational outcomes? (pp. 3-34). Mahwah, NJ: Lawrence Erlbaum.

El Nokali, N. E., Bachman, H. J., \& Votruba-Drzal, E. (2010). Parent involvement and children's academic and social development in elementary school. Child Development, 81, 9881005.

Falbo, T., Lein, L., \& Amador, N. A. (2001). Parental involvement during the transition to high school. Journal of Adolescent Research, 16, 511-529.

Fan, X., \& Chen, M. (2001). Parental involvement and students' academic achievement: A metaanalysis. Educational Psychology Review, 13, 1-22.

Flouri, E., Buchanan, A., \& Bream, V. (2002). Adolescents' perceptions of their fathers' involvement: Sig- nificance to school attitudes. Psychology in the Schools, 39, 575-582.

Gonzales-DeHass, A. R., Willems, P. P., \& Holbein, M. F. (2005). Examining the relationship between parental involvement and student motivation. Educational Psychology Review, 17, 99-123. 
Green, C. L., Walker, J. M. T., Hoover-Dempsey, K. V., \& Sandler, H. M. (2007). Parents' motivations for involvement in children's education: An empirical test of a theoretical model of parental involvement. Journal of Educational Psychology, 99, 532-544.

Grief, J. L., \& Grief, G. L. (2004). Including fathers in school psychology literature: A review of four school psychology journals. Psychology in the Schools, 41, 575-580.

Grolnick, W. S., Gurland, S. T., DeCourcey, W., \& Jacob, K. (2002). Antecedents and consequences of mothers' autonomy support: An experimental investigation. Developmental Psychology, 38, 143-155.

Hardre, P. L., \& Reeve, J. (2003). A motivational model of rural students' intentions to persist in, versus drop out of, high school. Journal of Educational Psychology, 95, 347-356.

Hill, N. E., \& Taylor, L. C. (2004). Parental school involvement and children's academic achievement: Prag- matics and issues. Current Directions in Psychological Science, 13, $161-164$.

Hill, N. E., \& Tyson, D. F. (2009). Parental involvement in middle school: A metaanalytic assessment of the strategies that promote achievement. Developmental Psychology, 45, 740-763.

Hornby, G. (2011). Importance of parental involvement. In G. Hornby (Ed.), Parental involvement in childhood education. New York: Springer.

Izzo, C. V., Weissberg, R. P., Kasprow, W. J., \& Fendrich, M. (1999). A longitudinal assessment of teacher perceptions of parent involvement in children's education and school performance. American Journal of Community Psychology, 27(6), 817-839.

Loeber, R., Green, S. M., \& Lahey, B. B. (1990). Mental health professionals' perception of the utility of children, mothers, and teachers as informants on childhood psychopathology. 
Journal of Clinical Child Psychology, 19, 136-143.

McBride, B. A., Schoppe-Sullivan, S. J., \& Moon-Ho, H. (2005). The mediating role of fathers' school involvement on student achievement. Applied Developmental Psychology, 26, 201-216.

Niggli, A., Trautwein, U., Schnyder, I., Ludtke, O., \& Neumann, M. (2007). Parental homework support can be beneficial, but parental intrusion is detrimental: Family background, parental homework super- vision, and performance gains. Psychologie In Erziehung und Unterricht, 54, 1-14.

Park, S., \& Holloway, S. D. (2013). No parent left behind: Predicting parental involvement in adolescents' education within a sociodemographically diverse population. The Journal of Educational Research, 106, 105-119.

Pomerantz, E. M., Moorman, E. A., \& Litwack, S. D. (2007). The how, whom, and why of parents' involvement in children's academic lives: More is not always better. Review of Educational Research, 77, 373-410.

Potvin, P., Doré-Côté, A., Fortin, L., Royer, E., Marcotte, D., \& Leclerc, D. (2004). Le questionnaire de dépistage des élèves a risque de décrochage au secondaire. Québec: Centre de transfert pour la réus- site éducative du Québec (CTREQ).

Potvin, P., Fortin, L., \& Rousseau, M. (2009). Qualités psychométriques du questionnaire de dépistage des élèves à risque de décrochage scolaire. Revue de Psychoéducation, 38, $263-278$.

Rogers, M., Markel, C., Midgett, J. D., Ryan, B. A., \& Tannock, R. (2014). Measuring children's perceptions of parental involvement in conjoint behavioral consultation: Factor structure and reliability of the Parental Support for Learning Scale. Assessment for Effective 
Intervention, 39, 170-181.

Rogers, M., Theule, J., Ryan, B., Adams, L., \& Keating, L. (2009). Parental involvement and children's school achievement: The mediating role of children's academic competence. Canadian Journal of School Psychology, 24, 34-57.

Sanders, M. G., \& Epstein, J. L. (2000). Building school family community partnerships in middle and high schools. In M. G. Sanders (Ed.), Schooling students placed at risk: Research, policy, and practice in the education of poor and minority adolescents (pp. 339-361). Mahwah, NJ: Erlbaum.

Sebastian, C., Burnett, S., \& Blakemore, S. J. (2008). Development of the self-concept during adolescence. Trends in Cognitive Sciences, 12, 441-446.

Seginer, R. (2006). Parents' educational involvement: A developmental ecological perspective. Parenting: Science and Practice, 6, 1-48.

Shumow, L., \& Miller, J. D. (2001). Parents' at-home and at-school academic involvement with young adolescents. The Journal of Early Adolescence, 21, 68-91.

Simpkins, S. D., Weiss, H. B., McCartney, K., Kreider, H. M., \& Dearing, E. (2006). Motherchild relationship as a moderator of the relation between family educational involvement and child achievement. Parenting: Science and Practice, 6, 49-57.

Soenens, B., \& Vansteenkiste, M. (2010). A theoretical upgrade of the concept of parental psychological control: Proposing new insights on the basis of self-determination theory. Developmental Review, 30, 74-99.

Tabachnick, B. G., \& Fidell, L. S. (1996). Using multivariate statistics (3rd ed.). New York: Harper Collins Publishers.

van Assema, P., Glanz, K., Martens, M., \& Brug, J. (2007). Differences between parents' and 
adolescents' perceptions of family food rules and availability. Journal of Nutrition Education and Behavior, 39, 84-89.

Westmoreland, H., Bouffard, S., O’Carroll, K., \& Rosenberg, S. (2009). Data collection instruments for evaluating family involvement. Cambridge, MA: Harvard Family Research Project. 


\section{Tables and Figures}

Table 1 Items in PSLS-AS-mother factors and associated factor loadings

\begin{tabular}{|c|c|c|}
\hline Item & Factor name and item description & $\overline{\text { Factor loading }}$ \\
\hline \multicolumn{3}{|c|}{ Factor 1: controlling involvement } \\
\hline 23 & ...constantly nagging about school work & 0.71 \\
\hline 26 & .... a lot of pressure to achieve at school & 0.70 \\
\hline 15 & ...punishes me if I do poorly at school & 0.70 \\
\hline 31 & ...very strict when it comes to my education & 0.69 \\
\hline 24 & ...tries to make me feel guilty when I do poorly & 0.69 \\
\hline 1 & ...poor grades, will restrict my free time/take away privileges & 0.65 \\
\hline 20 & ...disappointed in my school work & 0.64 \\
\hline 14 & ...disappointed in my school work & 0.64 \\
\hline 30 & ...disapproving of my school work & 0.62 \\
\hline 6 & ...insists I do school work her way & 0.57 \\
\hline 19 & ...feels like she is trying to take over my school work & 0.53 \\
\hline 10 & ...thinks I am lazy when it comes to my work & 0.53 \\
\hline \multicolumn{3}{|c|}{ Factor 2: Autonomy supportive involvement } \\
\hline 18 & ...tries to make me feel confident in my school work & 0.77 \\
\hline 4 & ...supports me in the things I do at school & 0.77 \\
\hline 9 & ...happy to talk to me about my learning & 0.77 \\
\hline 11 & ...listens to my perspective/opinion when I am struggling & 0.73 \\
\hline 27 & ...supports my school-related choices & 0.69 \\
\hline 12 & ...likes me to come to her for help & 0.68 \\
\hline 32 & ...very patient when it comes to my education & 0.47 \\
\hline 25 & ...allows me to make choices regarding my learning & 0.45 \\
\hline
\end{tabular}

Table 2 Items in PSLS-AS-Father factors and associated factor loadings

\begin{tabular}{|c|c|c|}
\hline Item & Factor name and item description & 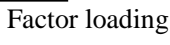 \\
\hline \multicolumn{3}{|c|}{ Factor 1: Autonomy supportive involvement } \\
\hline 4 & ...supports me in the things I do at school & 0.82 \\
\hline 9 & ...happy to talk to me about my learning & 0.80 \\
\hline 18 & ...tries to make me feel confident in my school work & 0.76 \\
\hline 27 & ...supports my school-related choices & 0.74 \\
\hline 11 & ...listens to my perspective/opinion when I am struggling & 0.73 \\
\hline 12 & ...likes me to come to him for help & 0.66 \\
\hline 32 & ...very patient when it comes to my education & 0.55 \\
\hline 25 & ...allows me to make choices regarding my learning & 0.50 \\
\hline \multicolumn{3}{|c|}{ Factor 2: Controlling involvement } \\
\hline 23 & ...constantly nagging about school work & 0.77 \\
\hline 24 & ...tries to make me feel guilty when I do poorly & 0.72 \\
\hline 20 & ...disappointed in my school work & 0.68 \\
\hline 15 & ...punishes me if I do poorly at school & 0.68 \\
\hline 31 & ...very strict when it comes to my education & 0.68 \\
\hline 26 & .... a lot of pressure to achieve at school & 0.66 \\
\hline 30 & ...disapproving of my school work & 0.62 \\
\hline 1 & ...poor grades, will restrict my free time/take away privileges & 0.62 \\
\hline 19 & ...feels like he is trying to take over my school work & 0.60 \\
\hline 6 & ...insists I do school work his way & 0.60 \\
\hline 10 & ...thinks I am lazy when it comes to my work & 0.57 \\
\hline
\end{tabular}


This is a post-peer-review, pre-copyedit version of an article published in 'Learning Environments Research'. The final authenticated version is available online at: https://doi.org/10.1007/s10984-018-9262-4.

Table 3 Correlations between the PSLS-AS factors and the DEMS Scale

\begin{tabular}{lllll}
\hline DEMS Scale & Mother control & $\begin{array}{l}\text { Mother auton- } \\
\text { omy support }\end{array}$ & Father control & $\begin{array}{l}\text { Father } \\
\text { autonomy } \\
\text { support }\end{array}$ \\
\hline Total dropout risk & $0.34^{* *}$ & $-0.50^{* *}$ & $0.38^{* *}$ & $-0.51^{* *}$ \\
Perceptions of school success & $0.31^{* *}$ & $-0.30^{* * *}$ & $0.32^{* *}$ & $-0.31^{* *}$ \\
Parental engagement & $0.30^{* *}$ & $-0.60^{* *}$ & $0.32^{* *}$ & $-0.58^{* *}$ \\
Educational aspirations & 0.07 & $-0.18^{* *}$ & $0.11^{*}$ & $-0.24^{* *}$ \\
Attitudes toward school & $0.24^{* *}$ & $-0.35^{* *}$ & $0.31^{* *}$ & $-0.35^{* *}$ \\
Parental supervision & $0.18^{* *}$ & $-0.23^{* *}$ & $0.25^{* *}$ & $-0.26^{* *}$ \\
\hline
\end{tabular}

$* p<0.05, * * p<0.01, * * * p<0.001$ 